\title{
Global cooperation of research and educational activities in the implementation of the Sustainable Development Goals
}

\author{
Viktor Zinchenko ${ }^{1, *}$, Viktoriia Levkulych ${ }^{2}$, Olha Palamarchuk ${ }^{3}$, and Mariia Debych ${ }^{4}$ \\ ${ }^{1}$ Doctor of Sciences (Philosophical), Principal researcher in Department of University Research \\ Activities of the Institute of Higher Education of the National Academy of Educational Sciences of \\ Ukraine, Kyiv, Ukraine \\ ${ }^{2}$ Candidate of Economic Sciences, Department of Accounting and Audit, Uzhhorod National \\ University, Uzhhorod, Ukraine \\ ${ }^{3} \mathrm{PhD}$ in Educational Sciences, Senior researcher in Department of Quality Assurance of Higher \\ Education of the Institute of Higher Education of the National Academy of Educational Sciences of \\ Ukraine, Kyiv, Ukraine \\ ${ }^{4}$ Doctor of Sciences (Education), Principal researcher in Department of Quality Assurance of Higher \\ Education of the Institute of Higher Education of the National Academy of Educational Sciences of \\ Ukraine, Kyiv, Ukraine
}

\begin{abstract}
The global community has 17 Sustainable Development Goals (SDGs) that are closely connected. Specific areas of actions are designed to realize their ambitious vision of a peaceful, socially inclusive world that uses natural resources at a constant level, with major changes at the economic, social, research, educational and environmental levels, with universal respect for human rights, equality and self-determination of all people, as well as environmental protection and social development. UN, UNESCO, OECD, EU implemented strategies and tactics for the development of education (in particular, higher) and science in the context of the formation of sustainable development of society «Sustainable Development Goal 4 - SDG-Education 2030» and «Quality Education» according to «The 2030 Agenda for Sustainable Development». Sustainable Development Goal 4 (SDG 4) - aims to provide comprehensive and equitable quality education and promote lifelong learning opportunities. Given the global scarcity of resources and related distribution issues, SDR should contribute to the peaceful coexistence of freedom and prosperity and an enabling environment for present and future generations. SDG facilitates the communication of sustainable development and its specific implementation. Education for sustainable development should be viewed as a common problem and a regulatory idea throughout the global education and science system.
\end{abstract}

\section{Introduction}

The need for this research is caused by the integration of higher education in Ukraine into the European Higher Education Area and the European Research Area; the need to study the problem of compliance of strategic guidelines of higher education and its specific educational models with the needs of civilizational progress towards a sustainable future, peace, mutual understanding, mutual respect and care for the environment (as reflected in the scientific literature through the concepts of information society, knowledge society,

* Corresponding author: v.zinchenko@ihed.org.ua 
sustainable development, globalization, internationalization of higher education, culture of peace, global citizenship, etc.).

Implementation of research results will increase the level and quality of internationalization of higher education, the formation of a worldview to stimulate and ensure sustainable development of society, increase social responsibility of higher education and strengthen its function of serving society, how to better integrate and adapt global social, institutional and systemic educational and scientific processes to the relevant national environment. All these are crucial and interesting new questions, many of which are still need to be answered.

\section{Research methodology}

Prior to the analysis and development of the study, the issues of philosophical and educational substantiation of strategies of sustainable development of society in the processes of institutionalization of the world global system as a holistic and multilevel sphere of interaction of economies, societies, states, social institutions, cultures, peoples, nations, worldviews and mankind in the context of internationalization of educational and scientific space; development and definition of mechanisms for the implementation of a comprehensive strategy for the internationalization of higher education to ensure the sustainable development of society; value dimensions of higher education strategies, formation of global citizenship, features of communication strategies in the context of internationalization for sustainable development of society; international publishing activity as a component of the strategy of higher education in the conditions of internationalization for sustainable development of society; strategies of higher education in the light of generational change were insufficiently developed in the national scientific field [1].

Knowledge and information, development of ICT, integration processes and globalization depend on the principles of market regulation in the field of higher education. The role of higher education institutions is to ensure global cooperation of research and educational activities in the implementation of innovative development of national economies, that are strengthened by the priority of state regulation in higher education based on the principles of the European Higher Education Area and the European Research Area. In this regard, the purpose of this work is to generalize the theoretical and methodological foundations of internationalization of higher education, based on international legal principles that should serve the purpose of enhancing the quality of higher education and strengthening their social function to ensure the interests of sustainable society.

\subsection{Leading organizations and strategic documents.}

The last Conference of Ministers of Higher Education of the European Higher Education Area «Embrace the challenge, create new opportunities and cancel differences» [2] outlined the EHEA's vision of the fundamental values of higher education and democracy and the rule of law for global cooperation and education.

UN Resolution «Transforming our world: the 2030 Agenda for Sustainable Development» (2015) [3] presents a new, holistic concept of sustainable development, which includes 17 goals and 169 relevant tasks [4,5].

In 2009 World Conference on Higher Education: The New Dynamics of Higher Education and Research for Societal Change and Development; (UNESCO communiqué) [6], substantiating the need to strengthen partnerships and coordination at the national, regional and international levels to ensure quality and sustainability of higher education systems worldwide.

UNESCO reports $(2013,2014,2015)$ on the prospects of education for global citizenship in the context of the challenges of the XXI century. 
The Paris Communiqué states: «Academic freedom and integrity, institutional autonomy, participation of students and staff in higher education governance, and public responsibility for and of higher education form the backbone of the EHEA» [7]. The communiqué also ambitiously claims: «We will foster and extend integrated transnational cooperation in higher education, research and innovation, for increased mobility of staff, students and researchers, and for more joint study programs throughout the entire EHEA» and states: «We commit to developing the role of higher education in securing a sustainable future for our planet and our societies and to finding ways in which we, as EHEA Ministers, can contribute to meeting the United Nations Sustainable Development Goals at global, European and national levels» [7]. These policies, in our opinion, are vital in the global cooperation of research and educational activities in the implementation of the Sustainable Development Goals.

The communiqué of the Conference of European Ministers of Higher Education «Bologna Process to 2020 - European Higher Education Area in the New Decade» [8]provides an overview of the achievements of the Bologna Process and priorities for the development of the European Higher Education Area (EHEA) in the new decade.

Communication from the Commission (2010) «Europe 2020: A strategy for smart, sustainable and inclusive growth» [9], sets out in particular the priority objectives of higher education for sustainable development.

Communique of the European Commission to the European Parliament, the Council of Europe, the European Economic and Social Committee and the Committee of the Regions «European Higher Education in the World» (2013) [10], presents a comprehensive internationalization strategy.

Sustainable innovation development through the training of highly qualified professionals, the creation and dissemination of knowledge, the formation of intellectual, social and spiritual capital of a society ready for the challenges of the future is based on a significant number of policies agreed by governments recommended by international institutions, namely: World Social Science Report. Knowledge Divides. International Social Science Council (ISSC). - UNESCO, 2010 - on the «knowledge society» and its problems, in particular, on the need to overcome fragmentation and excessive specialization in the social sciences and humanities; to bridge the gap between research and the needs of society; on overcoming disciplinary constraints and the need for interdisciplinary, multidisciplinary and transdisciplinary research; on the need to study the phenomenon of dramatic growth of the role of communication in various spheres of public life; on the relevance of new areas of research that are formed at the intersections of different disciplines (transdisciplinary, transversality, transferability).

According to Lisbon Declaration [11] «Europe's Universities beyond 2010: Diversity with a Common Purpose», supporting best practices in a global context, the European University Association (EUA) has announced an intensification of the role of universities in helping civil society to meet the challenges of the 21 st century; on the key task of universities - to prepare young people to fulfill their role in the knowledge society, in which social and cultural development depend on the ability of young people to be its active subject; on basic research, which is the basis of university education; on the responsibility of European universities for the development of an integration society; on stimulating critical thinking and active participation of students in social reform.

In the Leuven Communiqué (Leuven and Leuven-la-Neuve, 28-29 April 2009) Communique of the Conference of European Ministers Responsible for Higher Education [8] held under the slogan «The Bologna Process 2020 - The European Higher Education Area in the new decade», which focus on European higher education institutions to further internationalize their activities and participate in global cooperation for sustainable development. 
The European Commission has presented a 2016 communiqué, «Investing in Europe's Youth» [12], which emphasizes the importance of new opportunities for young people through quality education, including higher education. The key issue is the quality of education, which is crucial for the development of opportunities for the younger generation to build the EU.

National report on the state and prospects of education in Ukraine [13], which provides a comprehensive analysis of the state and development of national education over the 25year period of independence of Ukraine, identifies current educational problems, identifies their causes, offers scientifically sound ways to modernize national education in the context of globalization, European integration and national self-identification.

\subsection{The relevance of this work and the grounds for its implementation}

In recent years, in all regulations of international and European level, as well as scientific publications emphasize that the internationalization of higher education is not a self-sufficient goal, but should serve the purpose of improving the quality of education and strengthening its social function to ensure sustainable development.

At the global level, new global goals of sustainable development have been developed, set out in the UN document «2030 Agenda for Sustainable Development», adopted on September 23-24, 2015 [4]. Preparations for these goals started in 2012, when the international education community, led by UNESCO and the United Nations Children's Fund (UNICEF), began extensive and intensive consultations to determine the future agenda for education. This great process culminated in the Muscat Agreement, adopted at the World EFA Meeting in Oman in May 2014, and represents a common vision for future education.

It is now possible to provide a more ambitious vision of higher education in the light of the 2030 Agenda for Sustainable Development [3]. This paper proposes a new, holistic concept of sustainable development, which includes 17 goals and 169 relevant tasks, that are extremely crucial for the world. It is expected that these comprehensive, far-reaching and human-centered goals and objectives will be included in the agenda of all nations, people and all segments of society. The new goals of sustainable development are universal, and all Member States must strive to achieve them through multilateral cooperation in close cooperation with civil society, business, scientific community and UN agencies.

The integration of these goals into the internationalization strategy in the field of higher education, especially the internationalization of programs and plans (so-called «internationalization at home») and international cooperation and partnership have been actively implemented in recent years by research institutions and higher education institutions around the world, for instance: the University of Copenhagen (Denmark), Keio University (Japan), Ludwig Maximilian University of Munich (Germany), Uppsala University (Sweden), Brock-Carlton University (Canada), University of Sydney (Australia), University of Vienna (Austria), European University Association (EU), Harvard University, Federal University of Colorado, University of Colorado and others.

Studying the experience of different countries and universities in the development and implementation of higher education strategies in the context of internationalization for sustainable development of society will identify and justify relevant to the needs of sustainable development of Ukrainian society strategic priorities and principles of higher education reform [14].

The goals of the «The 2030 Agenda for Sustainable Development» [4] are still insufficiently integrated into the processes of higher education reform in Ukraine. Crucial for our study are the objectives: 4. To provide a comprehensive and equitable quality education and to encourage the creation of lifelong learning opportunities for all; 
5. Ensuring gender equality and empowerment of women and girls; 16. Promoting a peaceful and open society for sustainable development, ensuring access to justice for all and creating effective, accountable and participatory institutions at all levels; 17. Strengthen the means of implementation and intensify work in the framework of the Global Partnership for Sustainable Development.

An important component of so-called «political pedagogies» focused on strengthening democracy and sustainable development is multicultural education, education for peace and a new direction - global civic education. Global civic education was implemented in the Sustainable Development Strategy in 2013 and has since attracted increasing attention from researchers and educators-practitioners.

The whole complex of these «political pedagogies» is still insufficiently implemented in higher education and is not perceived as a priority area of educational reforms, while UNESCO and UN documents and reports constantly emphasize that education should not only be a pass to the labor market, but has a strong potential sustainable future and a better world. Therefore, education policy should promote peace, mutual respect and care for the environment, as UN Secretary-General Ban Ki-moon emphasized in his report «Global Education First» [15]. This idea is the basis for determining the topic and direction of our study.

\section{Results of the research}

The global community has 17 Sustainable Development Goals (SDGs) that are closely linked. Specific areas of action are designed to realize their ambitious vision of a peaceful, fair, socially inclusive world that uses natural resources at a constant level, with major changes at the economic, social and environmental level, universal respect for human rights, equality and self-determination of all people, as well as environmental protection and social development.

To achieve this educational goal, UNESCO has developed the World Program of Action for Education for Sustainable Development, which was adopted by the UN at its General Assembly in a resolution in 2015. In addition to the component in Goal 4 (Inclusive, Fair and Quality Education), the Global Program of Action should also contribute to Goal 12 (Sustainable Consumption) and Goal 13 (Combating Climate Change).

Education for Sustainable Development (SDR), given the global scarcity of resources and related distribution issues, should contribute to the peaceful coexistence of freedom and prosperity and an enabling environment for present and future generations. Critical reflection of one's own reality of life, social conditions, currently existing models of thoughts and value judgments is aimed at responsibility and maturity of the individual. People of all ages, genders and cultures should be supported in developing alternative ideas about a sustainable future and to work creatively with others to realize these visions. SRF not only raises awareness of the complexity of the problems, but also facilitates the communication of sustainable development and its specific implementation. The aim is to develop the ability for critical reflection and systematic and future-oriented thinking, as well as for practical implementation that promote sustainable development.

Education for sustainable development must be seen as a common problem and a regulatory idea throughout the global education and science system. Different forms of global cooperation viewed as a standard are vital for the overall thinking, environmental, economic and social dimension.

UN, UNESCO, OECD, EU adopted and implemented strategy and tactics for the development of education (and, in particular, higher) in the context of the formation of sustainable development of society «Sustainable Development Goal 4 - SDG-Education 2030» and «Quality Education» according to The 2030 Agenda for Sustainable Development». To achieve this educational goal, UNESCO has developed a World 
Program of Action on Education for Sustainable Development, which was adopted by the UN at its General Assembly in 2015 in a separate resolution.

Sustainable Development Goal 4 (SDG 4) - the goal of education and quality conditions for research (inclusive, equitable and quality education) - aims to provide comprehensive and equitable quality education and promote lifelong learning opportunities. SDG 4 consists of 10 goals.

Failure to take this into account is negative both for the institutions of education and science, and for the general public needs of development, formation and implementation of a stable (rather than stagnant and / or regressive) type of development of society and the state. For example, the latest report of the Organization for Economic Co-operation and Development (OECD) «Education at a Glance: OECD Indicators» examines how education is becoming global and what the positive / negative, problematic prospects are. It provides data on the development, funding and efficiency of education systems in 35 OECD countries and a number of partner countries.

For the first time, two new indicators provide comparative data on the level of success in higher education and on the criteria for access to higher education. One section is devoted to the educational policy goal of the 2030 Program. Higher academic and professional education remains popular and continues to generate high incomes for both individuals and taxpayers. However, new data show that the differences between individual areas of research are significant. This follows from recent OECD research.

The report shows that economics, administrative and legal sciences are the most popular areas in OECD countries. Every fourth student starts studying in these fields. In contrast, on average, only 16 percent study engineering annually and only 5 percent study computer science, even if the employment rate of these graduates exceeds 90 percent in many countries. In Germany, for example, law and economics are in demand among first-year students, similar to the OECD average. With an employment rate of about $90 \%$, all three entities reach similar values.

In the social sciences and humanities, the employment rate is $84 \%$, but still higher for adults who have only a vocational education or a high school diploma. Therefore, the activities of Ukrainian free economic zones should take into account that:

- The UN and UNESCO understand education as a comprehensive and necessary basis for the development of democracy and human rights, as well as the strengthening of global citizenship and sustainable development. The SDG 4 Global Sustainability Goal is also UNESCO's current integrated education program. Member States have adopted it as a concrete basis for achieving the global goal of education.

- The OECD monitors experience and resource data globally to monitor sustainability targets. In addition, policy coherence reports, progress analyzes, etc. are prepared, such as «OECD and Sustainable Development Goals: Achieving Common Goals and Objectives».

- The European Union seeks to integrate sustainable development goals into all its policies and to establish sustainable development as a guiding principle of EU policy.

In January 2019, the European Commission presented a reflection paper on the EU's contribution to the global goals of sustainable development. The Council of the European Union called for speeding up the implementation of the 2030 Agenda in its conclusions.

Education is one of the key prerequisites for meeting the goals of the 2030 Agenda. Therefore, education has a key role to play in seeing a fair, peaceful and sustainable society. The world community has set its own goal (SDG 4): «To provide inclusive, equal and quality education and to promote lifelong learning opportunities for all». All education partners around the world must be involved to achieve this goal. The «2030 Agenda» also defines pedagogical concepts for the development of competence in understanding sustainability within the framework of the educational goal. 
The principles of education, training, educational issues and interdisciplinary topics are developed in consortia of educational, scientific, governmental, public and public institutions and associations, in particular: education for sustainable development, global civic education and global learning, political education, environmental education, gender issues, education, intercultural education, education in the field of human rights.

\section{Conclusions}

Interdisciplinary links are important for common thinking on the environmental, economic and social dimensions. In addition, education for sustainable development, global civic education, and other learning principles and educational approaches provide an educational framework for sustainability in all its dimensions. The learning process should develop knowledge, competences and abilities, values and attitudes so that young people can play an active role in solving local and global social, economic and environmental problems. In this sense, education raises awareness of the complexity of global challenges and promotes critical reflection, systematic, future-oriented thinking and, ultimately, action.

Scientific research is primarily due to the need to study the problem of compliance of strategic guidelines of higher education and its specific educational models with the needs of civilizational progress towards a sustainable future, peace, mutual understanding, mutual respect and care for the environment (as reflected in the scientific literature society, knowledge society, sustainable development, globalization, internationalization of higher education, culture of peace, global citizenship, multicultural education, gender equality, etc.).

Addressing this issue is due to the urgent practical needs of higher education reform in accordance with world quality standards and existing target priorities.

Global institutional transformations are currently taking place for the sustainable development of society in the context of the internationalization of higher education and science. One of the main features of the modern stage of development of world civilization is the globalization of all spheres of human social life - cultural, informational, economic. Various concepts of globalization are developed and arised. To understand the modern world as a whole, economic and social system, the term "internationalization" has long been widely used.

Science used to talk only about the internationalization of the economy, social and cultural life, and so on. However, today this concept has spread to all systemic and institutional levels and structures.

The experience of the strategy for sustainable development in the context of education and science in the OECD and the EU focuses on the importance of prioritizing the contribution of education to human rights, peace and responsible citizenship from local to global levels, gender equality, sustainable development and health.

The knowledge, skills, values and attitudes are needed by citizens to lead productive lives, make informed decisions and take active roles at the local and global levels in addressing global challenges can be acquired through Education for Sustainable Development (SDF) and Global Citizenship Education), which includes issues of global transformation, sustainable development, peace and human rights education, as well as intercultural education and education for international understanding. We believe that, both in the context of the direction of European integration of education and science, and strategies for sustainable development of society - «SRF» and «GOG» should be present in the activities of the Free Economic Zone of Ukraine. The content of such education should be relevant with an emphasis on both theoretically applied and cognitive aspects of education and training.

Almost every developed country has extensive experience in building a system of higher education. The results of the analysis of this experience can contribute to the 
development and enrichment of the domestic education system, avoid the recurrence of mistakes and the opportunity to discover new approaches to solving a number of problems in this area.

\section{References}

1. V. V. Zinchenko, Perspect. Sci. Educ. 44, 10 (2020)

2. In Conf. EHEA Minist. (2020)

3. Commite, Resolution Adopted by the General Assembly on 25 September 2015 (2015)

4. Transforming Our World: The 2030 Agenda for Sustainable Development (2018)

5. S. M. A. Ehsan, J. Contemp. Gov. Public Policy 2, 45 (2021)

6. UNESCO, The New Dynamics of Higher Education and Research for Societal Change and Development (2009)

7. P. Communique, Dokumentiv Konferentsiyi Ministriv Osvity Yevropeys'koho Prostoru Vyshchoyi Osvity (2018)

8. European Ministers Responsible for Higher Education, The Bologna Process 2020 The European Higher Education Area in the New Decade (2009)

9. E. COMMISSION, A Strategy for Smart, Sustainable and Inclusive Growth (2020)

10. E. COMMISSION, European Higher Education in the World (2013)

11. EUA, The Lisbon Declaration Europe's Universities beyond 2010 : Diversity with a Common Purpose (2010)

12. E. Commission, 14. Communication from the Commission to the European Parliament, the Council, the European Economic And Social Committee and the Committee of the Regions - Investing In Europe's Youth - Investing In Europe's Youth. (2016)

13. 25th anniversary of Ukraine's Independence, National Report on the State and Prospects of the Development of Education in Ukraine. Kyiv: Ped. Opinion (2016)

14. V. V. Zinchenko, V. V. Levkulych, V. V. Levkulych, and V. Y. Svyshcho, IOP Conf. Ser. Earth Environ. Sci. 635, 012001 (2021)

15. United States, Global Education First Initiative (2012) 